\title{
Gender Norms and Attitudes about Childcare Activities Presented on Father Blogs
}

\author{
Kai Lukoff \\ University of Washington \\ Seattle, USA \\ kai1@uw.edu
}

\author{
Carol Moser \\ University of Michigan \\ Ann Arbor, USA \\ moserc@umich.edu
}

\author{
Sarita Schoenebeck \\ University of Michigan \\ Ann Arbor, USA \\ yardi@umich.edu
}

\begin{abstract}
Father involvement is important for child well-being. However, fathers still do significantly less childcare than mothers, due in part to traditional gender norms. This research investigates whether incorporating do-it-yourself (DIY) language and imagery into parenting blogs is an effective mechanism for boosting fathers' willingness to perform childcare activities. We conducted a betweensubjects experiment with 374 participants in the U.S. who responded to ten parenting blog posts. Subjects were randomized to view posts with either DIY or neutral language and either routine childcare activities (e.g., changing diapers) or interactive ones (e.g., finger painting). Results show that DIY language actually decreases a father's willingness to do a childcare activity. Further, fathers underestimate how socially appropriate it is for them to perform childcare activities and this misperception relates to their willingness to get involved. We draw on social norms literature to recommend next steps for designing interfaces to support father involvement in childrearing.
\end{abstract}

\section{Author Keywords}

Fathers; childcare; masculinity; norms; DIY; blogs.

\section{ACM Classification Keywords}

H.5.m. Information interfaces and presentation (e.g., HCI): Miscellaneous.

\section{INTRODUCTION}

Though fathers have become more active in their parenting roles over the past 50 years [26,27,29], work imbalances persist $[15,21,34,41]$. Even though mothers have entered the workforce in greater numbers, they continue to do more housework and childcare than fathers [27,29,42]. Father involvement in heterosexual relationships correlates with their children having fewer behavioral problems, increased social stability, greater developmental progress, higher educational achievement, and stronger relationships

Permission to make digital or hard copies of all or part of this work for personal or classroom use is granted without fee provided that copies are not made or distributed for profit or commercial advantage and that copies bear this notice and the full citation on the first page. Copyrights for components of this work owned by others than the author(s) must be honored. Abstracting with credit is permitted. To copy otherwise, or republish, to post on servers or to redistribute to lists, requires prior specific permission and/or a fee. Request permissions from Permissions@acm.org.

CHI 2017, May 06 - 11, 2017, Denver, CO, USA

Copyright is held by the owner/author(s). Publication rights licensed to ACM.

ACM 978-1-4503-4655-9/17/050\$15.00

DOI: http://dx.doi.org/10.1145/3025453.3025767
$[12,22,38]$. In the U.S., many government and nonprofit organizations have worked to support greater father involvement (e.g., the National Center for Fathering). Recently, HCI research has also begun to focus on fathers' use of social media sites related to their roles as fathers. That work suggests that fathers go online to seek support, but they often do so anonymously on sites like Reddit or privately on Facebook closed groups $[3,42]$. They do so for two reasons: first, fathers perceive a social norm against fathers disclosing parenting challenges publicly [3] and second, many parenting resources are designed for, and used primarily by, mothers $[3,42]$. For example, the website, BabyCenter.com, claims to be used by 8 out of 10 moms in the U.S. [5].

We use a feminist HCI lens to explore how interaction design decisions can promote fathers' engagement with their identities and roles as fathers [7]. Bardzell's theory of feminist HCI highlights its commitment to identity, equity, and empowerment [7]. Here, we build on recent work on fatherhood, Internet use, and DIY to investigate using the Internet as a platform to promote father involvement in childcare activities in support of equity in gender roles and responsibilities in the home.

\section{RESEARCH QUESTIONS}

Social norms are the rules or behaviors that are considered acceptable in society $[13,39]$. Recent work suggests that fathers perceive there to be a social norm against fathers participating in offline parent groups (e.g., meetups) because such groups are predominantly composed of mothers (e.g., [36]). The same phenomenon appears to persist online, with fathers choosing to locate private or anonymous groups for fathers (e.g., Reddit or Facebook closed groups) [3]. Social norms research describes how people can misperceive social norms [31] (e.g., believing other people perceive something to be more or less socially acceptable than they actually do), and these misperceptions impact people's own behavior [33]. To test whether gender norms persist and are misperceived in online portrayals of childcare activities, our first set of hypotheses are:

H1: Both fathers and mothers ("parents") perceive childcare activities described in a blog post as more appropriate for mothers than fathers

H2: Fathers underestimate the social norm about how appropriate it is for them to perform childcare activities in a blog post 
Studies of Americans' time use distinguishes between two types of childcare: routine activities and interactive activities $[10,35]$. Routine activities include diaper feeding, brushing teeth, medical care, and travel to activities. Interactive activities include helping, teaching, talking, reading, or playing [14]. Interactive activities are generally considered more enjoyable than routine ones [35]. Roeters et al. explain that "routine activities are less intensive, more obligatory in nature, in the sense that they cannot easily be postponed or curtailed, and have a lower intrinsic value than interactive activities" [37]. Bianchi et al.'s study of Americans' time use over a four-decade period shows that more parenting time is spent on routine activities than interactive ones [10] and that mothers do more of both kinds of activities than fathers, but especially of routine activities [10]. For fathers, the traditional gender role prioritizes interactive activities over routines ones [23]. Thus, we hypothesize that:

H3: Fathers express higher willingness to do interactive activities in a blog post than routine activities

H4: Parents express higher levels of approval of fathers doing interactive activities described in a blog post than routine activities

The do-it-yourself (DIY) movement has historically been associated with home maintenance and improvementtraditionally masculine activities located in masculine domestic spaces (e.g., sheds and garages) [2,9,17,18,24]. Much of the contemporary practice of DIY making (e.g., Make Magazine and Maker Fairs) remains male-centric $[1,17,25,40]$; both authors and audience are predominantly male, and being a "DIY maker" is often portrayed as a way of articulating and enacting fatherhood through providing children with "hands-on and engaged" personal time [24]. Recent research suggests that stay-at-home fathers embrace DIY projects to identify as self-provisioning [15] and to legitimize the care work they perform as masculine when sharing on blogs and social media [2,4]. We therefore investigate whether the addition of DIY language and imagery in online contexts can promote fathers' willingness to perform childcare activities:

H5: DIY language and imagery in a blog post increases fathers' willingness to perform a childcare activity

H6: DIY language and imagery in a blog post increases the social norm about how appropriate it is for fathers to perform a childcare activity

\section{METHOD}

Experiment Design: We designed a between-subjects experiment in which respondents read 10 blog posts about childcare activities and answered 5 questions for each post.Each post contained a single image, a brief description (ranging from 73-87 words), a short list of items needed, and the steps to do the activity (see Figure 1). Both the appearance of the blog and ideas for the activities were sourced from popular DIY parenting blogs and websites (sources were credited at the end of the experiment).

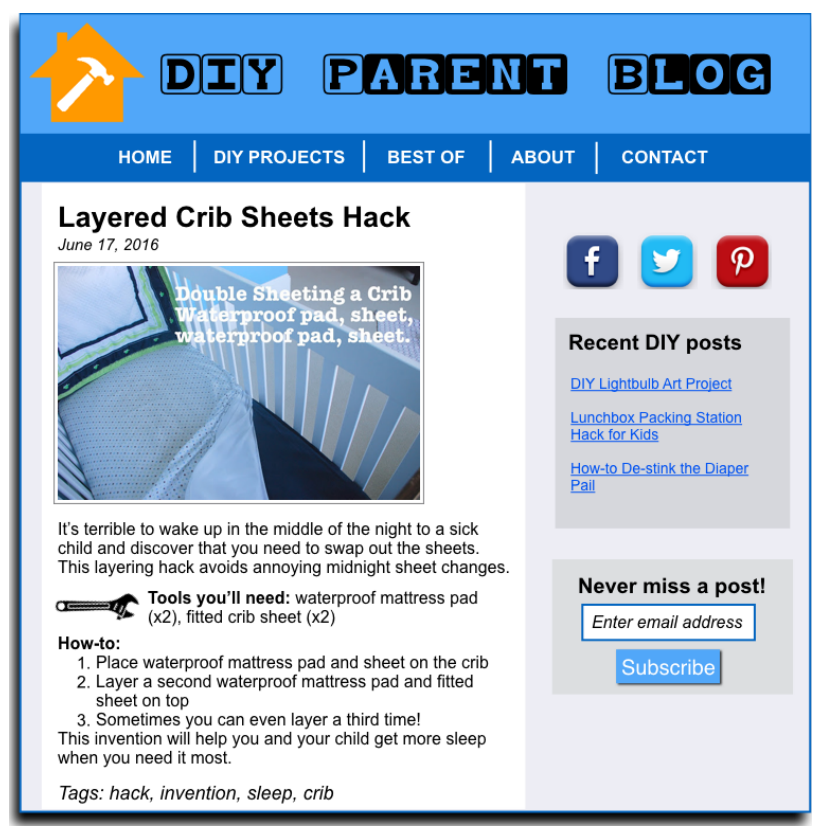

Figure 1. Sample blog post for DIY condition.

Respondents were randomized two times: first into a DIY or neutral condition, and second into a routine or interactive condition. Blog posts displayed in the DIY condition contained DIY language (i.e., "hack", "how-to", "DIY", "artisanal", "make", "create", and "build") and visuals (hammer overlaid on a house in the banner and a wrench in the description) (see Figure 1). These terms and visuals were designed based on existing DIY parent blogs. Blog posts displayed in the neutral conditions were the same as in the DIY except they did not include the DIY language and visuals. To ensure comparability, the text was carefully constructed so that it would also make sense without the DIY language and the neutral images were very similar in color, shape, and size to the DIY ones (see auxiliary material).

The final two sets of 10 blog topics selected for the routine and interactive conditions are shown in Table 1. To arrive at this set of topics, we first generated a list of over 40 routine and interactive childcare activities and then labeled them with the age range that the activity would be appropriate for. We then selected a range of ages for newborns to age 12 and balanced ages in each condition. The order of the blog posts was randomized.

For each blog post, respondents answered the same five questions in the Qualtrics survey platform. The first question measured father involvement using willingness as a proxy for involvement [23]: "How WILLING are you to perform this activity?" (Not at all willing to Extremely willing, 5point scale). The remaining four questions measured social norms: how appropriate do you think this activity is for fathers to do, how appropriate do you think this activity is for mothers to do, how appropriate would most fathers think this activity is for fathers to do, and how appropriate would most mothers think this activity is for mothers to do. Norms 


\section{Routine-Neutral}

Blowout Diaper Cleanup

Trim Baby's Nails

Layered Crib Sheets

Childproof Drawers

Baby Teething Solution

Bedtime Routine

The Snack Tray

Vacuum Cleaner Ponytail

Road Trip Map for Kids

Gum Removal Solution

\section{Interactive-Neutral}

No Mess Baby Paints

Sticky Ball for Baby

Tactile Balloons for Baby

Edible Fingerpaints

Play Binoculars

Lawnchair Batting Practice

Coffee Can Drums

3D Marshmallow Structures

Sharpie Mugs

Marshmallow Shooters

\section{Routine-DIY}

Blowout Diaper Cleanup Hack

How-to Trim Baby's Nails

Layered Crib Sheets Hack

DIY Childproof Drawers

DIY Baby Teething Solution

Bedtime Routine Hack

The Artisanal Snack Tray

DIY Vacuum Cleaner Ponytail

DIY Road Trip Map for Kids

DIY Gum Removal Solution

\section{Interactive-DIY}

DIY No Mess Baby Paints

DIY Sticky Ball for Baby

Make Tactile Balloons for Baby

Edible Fingerpaints Hack

DIY Play Binoculars

Lawnchair Batting Practice Hack

Create Coffee Can Drums

Build 3D Marshmallow Structures

DIY Sharpie Mugs

Build Marshmallow Shooters

Table 1. Routine and interactive blog topics.

questions used a 7-point scale from Extremely inappropriate to Extremely appropriate. After responding to the $10 \mathrm{blog}$ posts, respondents completed the Conformity to Masculine Norms Inventory-22, a validated 22-item scale measuring attitudes, behaviors, and beliefs towards masculine gender roles [28]. Respondents (fathers only) also completed The Inventory of Father Involvement-26, a 26-item validated scale measuring involvement in disciplining, school, time together, etc. [20]. Finally, respondents were asked demographic questions.

Recruitment and Participants: We recruited participants on Amazon Mechanical Turk $(\mathrm{n}=223)$ and Craigslist $(\mathrm{n}=151)$. We pre-screened for respondents who identified as parents of at least one child under the age of 13, regular internet users, 18 years of age or older, and as living in the United States. Median response time was 12.9 minutes. To ensure response quality, we used a minimum time threshold of 8 minutes for mothers and 10 minutes for fathers (since fathers had to complete an additional 26-item inventory). This time threshold led us to filter out $109(23 \%)$ of the original 483 responses, for a total of 374 participants.

Participants were 52\% female-identified and $48 \%$ maleidentified and came from 39 different states in the U.S. They ranged in age from 19-54 years (median $=33$ ). Eighty-eight percent of participants were either married or living with a partner. Of the participants in relationships, $94 \%$ reported a gender identity different from that of their partner, $4 \%$ were female-identified with a female partner and $2 \%$ were maleidentified with a male partner. Seventy percent of participants reported being employed full-time. Annual household incomes ranged from less than $\$ 25,000$ (14\% of participants), $\$ 25,000$ - $\$ 49,999$ (24\%), $\$ 50,000$ - \$74,999 $(35 \%)$, to more than $\$ 75,000(27 \%)$. In terms of education, $39 \%$ had some college or less, $38 \%$ had a bachelor's degree,

and $23 \%$ had completed some graduate school or a higher degree. Participants had a median of 2 children (mean = 1.94). Respondents ( $n=483$ before filtering) were paid $\$ 6$ upon completion of the study. This research was approved by the research team's Institutional Review Board.

Data Analysis: The data were analyzed using the R statistical software. Most of the results were analyzed using paired sample t-tests. For regression analysis, we used the lme4 package for fitting linear mixed-effects models [8]. We first tested for fixed effects because the data were hierarchically structured by respondent (each respondent responded to 10 different activities) and by childcare activity (10 routine activities and 10 interactive activities). ANOVA was used to compare a generalized least squares model against a multilevel model, and showed that the log-likelihood was greater for the multilevel model for each of our five questions (all $p<.001$ ) [16]. Regression analyses therefore included fixed effects for respondents and childcare activities. For each regression, the Bayesian information criterion (BIC) was used to determine which demographic variables to control for in the model (gender, education, income, employment status, and employment status of spouse/partner if applicable). Results are reported for the resulting "best fit" model, controlling for those variables selected by the BIC.

\section{RESULTS}

\section{Childcare Gender Norms Online (H1, H2)}

Our first two hypotheses examined how gender norms apply to childcare activities presented in a blog post. $\mathrm{H} 1$ states that parents perceive childcare activities as more appropriate for mothers than fathers. A paired-samples t-test found the expected difference when mothers $(M=7.15, S D=1.89)$ and fathers $(M=7.02, S D=1.88)$ were asked about the personal norm (what you think) $(t(3739)=5.50, p<.001, d$ (difference of means $)=0.13)$. The same was found when mothers $(M=$ $7.10, S D=1.88)$ and fathers $(M=6.85, S D=1.87)$ were asked about the injunctive norm (what most think) (t(3739) $=8.02, p<.001, d=0.25$ ).

$\mathrm{H} 2$ posits that fathers underestimate how socially appropriate it is for them to perform childcare activities presented in a blog post. Each father was asked both what you think $(M=$ $6.85, S D=1.83)$ and what most fathers think $(M=6.70, S D$ $=1.89) . \mathrm{A}$ paired-samples $\mathrm{t}$-test showed that fathers underestimate social appropriateness $(t(1779)=4.7, p<$ $.001, d=0.15)$. That is, fathers believed most fathers thought it less appropriate than was actually the case. Mothers, by comparison, did not underestimate social appropriateness $(t(1959)=0.99, p=.32)$; in other words, their perceptions about how socially appropriate it is versus how other mothers think is aligned. In addition, our multilevel regression model showed that fathers who perceived lower social appropriateness were less willing to perform childcare activities $(b=0.35, t(1734)=28.12, p<.001)$. Fathers' underestimation of the social appropriateness of fathers doing childcare activities in a blog is associated with lower willingness to perform those childcare activities. 


\section{Interactive vs. Routine Childcare Activities (H3, H4)}

The next two hypotheses addressed attitudes towards interactive versus routine childcare. For H3, a pairedsamples t-test found that fathers did not express greater willingness to perform interactive activities than routine activities presented in a blog post $(t(45)=0.66, p=.51)$. This finding is unexpected as previous research found that parents consider interactive childcare more enjoyable than routine [35] and that fathers spend a greater proportion of their child care time on interactive activities than mothers do [10].

With respect to $\mathrm{H} 4$, a paired-samples t-test found that parents do not express greater approval towards fathers performing interactive activities than routine ones. This held both when parents were asked what you think $(t(54)=0.06, p=.95)$ and when asked what most fathers think $(t(52)=0.36, p=.72)$. This suggests that parents believe it is just as appropriate for fathers to perform routine childcare activities from blogs like changing diapers as interactive ones like finger painting.

\section{DIY Language and Imagery (H5, H6)}

Our last two hypotheses addressed whether DIY language and imagery can increase father involvement. Surprisingly, our multilevel regression model found the opposite of that predicted by H5: DIY language and imagery decreased fathers' willingness to perform a childcare activity $(b=$ $-0.23, t(177)=2.47, p=.014)$. DIY also had a negative effect upon mothers' willingness, although it was not statistically significant $(b=-0.12, t(194)=1.39, p=.17)$.

H6 states that DIY language and imagery increases the perception of social appropriateness of fathers performing childcare activities. When participants were asked what you think, there was an effect in the opposite direction $(b=-0.17$, $t(372)=2.76, p=.006)$. In the case of what most parents think, the effect was again negative, but not statistically significant $(b=-0.19, t(373)=1.72, p=.09)$.

\section{DISCUSSION AND FUTURE WORK}

Our results confirm that long-standing gender norms around childcare persist online. Both mothers and fathers believe that it is less appropriate for fathers to do childcare activities depicted in a blog than it is for mothers to do them. Further, fathers misperceive the social norm: they think it is appropriate for them to do childcare but do not realize that other fathers also believe the same. However, we were not able to provide evidence for a mechanism (i.e., DIY) for mitigating those imbalances, and in fact, we found that DIY has a negative influence. It may be that parents perceive DIY and parenting to be independent activities, resulting in their aversion to the idea of explicitly combining them. Though we see a negative result, we believe it offers a valuable contribution to a research agenda focusing on what design opportunities are-or, as it turns out, are not-effective at promoting fatherhood involvement online.

Our results do suggest a potential next step to explore. Social norms literature shows that people regularly misperceive social norms (e.g., college students believing other students drink more alcohol than they do) [32]. Social norms research offers norms campaigns that correct a misperception as an effective approach for promoting desired social behaviors (in the example above, campus posters stating that the majority of college students drink less than is believed) [30]. Similarly, a norms campaign could promote father involvement online by describing how fathers are more involved than most people believe, which may encourage father participation in parenting sites that are traditionally more welcoming to mothers.

In her argument for feminism in interaction design, Bardzell emphasizes that males and females use technology in different ways, and argues that "the user" and "the home" should be framed as cultural and gendered constructs [7]. Recent work in HCI also suggests that gender identity and sexual identity influence parents' online experiences [11]. Though gender equity is important, it may be that collapsing parents into a single "user" as is often done on parenting sites (e.g., Parenting.com) does a disservice to designing experiences attuned to gendered social roles and expectations. At the same time, designing to meet gendered role expectations may risk reifying the social constructs of gender and gender norms that feminist HCI seeks to question and overturn. None of our respondents identified as a gender other than "male" or "female" though the option was available and only $6 \%$ of parents in our sample reported that they were in relationships with partners of the same gender identity. Capturing online childcare norms that considers the range of gender identities is important future work.

This work focused on blogs because both mothers and fathers use them and because they were a convenient platform to experimentally test designs (unlike noncustomizable parenting sites like BabyCenter, Facebook, or Reddit). Moreover, since our experiment was limited to internet users in the U.S., the findings may not extend to noninternet users and cultures outside of the U.S., where the role of fathers can be considerably different [23]. Future work could also explore whether our results are consistent in other online and cultural contexts.

Our goal is to uncover existing attitudes and potential design opportunities around promoting father involvement. We anchor this agenda in feminist HCI which is committed to equity, empowerment, and social justice [7]. Though motherhood in HCI has gained traction (e.g., [6,19]), fatherhood is a newer topic [3]. This work contributes insights around social norms and DIY related to father involvement and proposes opportunities for supporting gender equity with regards to childcare responsibilities.

\section{ACKNOWLEDGMENTS}

We thank Tawfiq Ammari and Matthew Kay for their insights. We thank the Mechanical Turk and Craigslist participants for their time. This material is based upon work supported by the National Science Foundation under Grant No. 1318143 and by funding from the Institute of Museum and Library Services \#RE-01-15-0086-15. 


\section{REFERENCES}

1. Morgan G. Ames, Jeffrey Bardzell, Shaowen Bardzell, Silvia Lindtner, David A. Mellis, and Daniela K. Rosner. 2014. Making Cultures: Empowerment, Participation, and Democracy - or Not? In Proceedings of the Extended Abstracts of the 32nd Annual ACM Conference on Human Factors in Computing Systems (CHI EA '14), 1087-1092.

2. Tawfiq Ammari, Silvia Lindtner, and Sarita Schoenebeck. Bringing the Shed into the Home: The Crafting of DIY Fatherhood. Under review.

3. Tawfiq Ammari and Sarita Schoenebeck. 2015. Understanding and Supporting Fathers and Fatherhood on Social Media Sites. In Proceedings of the 33rd Annual ACM Conference on Human Factors in Computing Systems (CHI '15), 1905-1914.

4. T. Ammari and S. Schoenebeck. 2016. "Thanks for your interest in our Facebook group, but it's only for dads": Social Roles of Stay-at-Home Dads. In Proceedings of the 19th ACM Conference on Computer-Supported Cooperative Work \& Social Computing (CSCW'16), 1363-1375.

5. babycenter. Company Overview. BabyCenter. Retrieved from www.babycenter.com/help-aboutcompany

6. Madeline Balaam, Judy Robertson, Geraldine Fitzpatrick, Rebecca Say, Gillian Hayes, Melissa Mazmanian, and Belinda Parmar. 2013. Motherhood and HCI. In CHI '13 Extended Abstracts on Human Factors in Computing Systems (CHI EA '13), 32153218.

7. Shaowen Bardzell. 2010. Feminist HCI: Taking Stock and Outlining an Agenda for Design. In Proceedings of the SIGCHI Conference on Human Factors in Computing Systems (CHI '10), 1301-1310.

8. Douglas Bates, Martin Mächler, Ben Bolker, and Steve Walker. 2015. Fitting Linear Mixed-Effects Models Using lme4. Journal of statistical software 67, 1: $1-48$.

9. Genevieve Bell and Paul Dourish. 2007. Back to the shed: gendered visions of technology and domesticity. Personal and Ubiquitous Computing 11, 5: 373-381.

10. Suzanne M. Bianchi, John P. Robinson, and Melissa A. Milke. 2006. The changing rhythms of American family life. Russell Sage Foundation.

11. Lindsay Blackwell, Jean Hardy, Tawfiq Ammari, Tiffany Veinot, Cliff Lampe, and Sarita Schoenebeck. 2016. LGBT Parents and Social Media: Advocacy, Privacy, and Disclosure during Shifting Social Movements. In Proceedings of the 2016 CHI Conference on Human Factors in Computing Systems (CHI '16), 610-622.
12. Natasha Cabrera and H. Elizabeth Peters. 2000. Public Policies and Father Involvement. Marriage \& family review 29, 4: 295-314.

13. Robert B. Cialdini, Carl A. Kallgren, and Raymond R. Reno. 1991. A Focus Theory of Normative Conduct: A Theoretical Refinement and Reevaluation of the Role of Norms in Human Behavior. In Advances in Experimental Social Psychology, Mark P. Zanna (ed.). Academic Press, 201-234.

14. Lyn Craig. 2006. Does Father Care Mean Fathers Share? A Comparison of How Mothers and Fathers in Intact Families Spend Time with Children. Gender and Society 20, 2: 259-281.

15. Andrea Doucet. 2004. "It's almost like I have a job, but I don't get paid": fathers at home reconfiguring work, care, and masculinity. Fathering 2, 3: 277.

16. A. Field, J. Miles, and Z. Field. 2012. Discovering Statistics Using R. SAGE Publications.

17. Sarah Fox, Rachel Rose Ulgado, and Daniela Rosner. 2015. Hacking Culture, Not Devices: Access and Recognition in Feminist Hackerspaces. In Proceedings of the 18th ACM Conference on Computer Supported Cooperative Work \& Social Computing (CSCW'15), 56-68.

18. Steven M. Gelber. 1997. Do-It-Yourself: Constructing, Repairing and Maintaining Domestic Masculinity. American quarterly 49, 1: 66-112.

19. Lorna Gibson and Vicki L. Hanson. 2013. Digital Motherhood: How Does Technology Help New Mothers? In Proceedings of the SIGCHI Conference on Human Factors in Computing Systems (CHI '13), 313-322.

20. Alan J. Hawkins, Kay P. Bradford, Rob Palkovitz, Shawn L. Christiansen, Randal D. Day, and Vaughn R. A. Call. 2002. The Inventory of Father Involvement: A Pilot Study of a New Measure of Father Involvement. The Journal of Men's Studies 10, 2: 183-196.

21. Arlie Hochschild and Anne Machung. 2012. The Second Shift: Working Families and the Revolution at Home. Penguin.

22. Michael E. Lamb. 2000. The History of Research on Father Involvement. Marriage \& Family Review 29, 2 3: $23-42$.

23. Michael E. Lamb. 2004. The Role of the Father in Child Development. John Wiley \& Sons.

24. Silvia Lindtner. 2014. Hackerspaces and the Internet of Things in China: How makers are reinventing industrial production, innovation, and the self. China Information 28, 2: 145-167.

25. Silvia Lindtner, Anna Greenspan, and David Li. 2015. Designed in Shenzhen: Shanzhai Manufacturing and Maker Entrepreneurs. In Proceedings of The Fifth 
Decennial Aarhus Conference on Critical Alternatives (AA '15), 85-96.

26. Gretchen Livingston. 2013. The rise of single fathers: A ninefold increase since 1960. Pew Research Center.

27. Gretchen Livingston. 2014. Growing number of dads home with the kids. Pew Research Center.

28. James R. Mahalik, Benjamin D. Locke, Larry H. Ludlow, Matthew A. Diemer, Ryan P. J. Scott, Michael Gottfried, and Gary Freitas. 2003. Development of the Conformity to Masculine Norms Inventory. Psychology of Men \& Masculinity 4, 1: 3.

29. Kim Parker and Wendy Wang. 2013. Modern Parenthood: Roles of Moms and Dads Converge as They Balance Work and Family. Pew Research Center.

30. Wesley H. Perkins. 2002. Social norms and the prevention of alcohol misuse in collegiate contexts. Journal of studies on alcohol. Supplement, 14: 164172.

31. Wesley H. Perkins and Alan D. Berkowitz. 1986. Perceiving the Community Norms of Alcohol Use among Students: Some Research Implications for Campus Alcohol Education Programming. The International journal of the addictions 21, 9-10: 961976.

32. Wesley H. Perkins, Philip W. Meilman, Leichliter, S. Jami, Jeffrey R. Cashin, and Cheryl A. Presley. 1999. Misperceptions of the norms for the frequency of alcohol and other drug use on college campuses. Journal of American College Health 47, 6: 253-258.

33. Deborah A. Prentice and Dale T. Miller. 1993. Pluralistic ignorance and alcohol use on campus: some consequences of misperceiving the social norm. Journal of personality and social psychology 64, 2: 243-256.
34. Erin M. Rehel. 2013. When Dad Stays Home Too: Paternity Leave, Gender, and Parenting. Gender \& Society. https://doi.org/10.1177/0891243213503900

35. John Robinson and Geoffrey Godbey. 2010. Time for life: The surprising ways Americans use their time. Penn State Press.

36. Aaron B. Rochlen, Ryan A. McKelley, and Tiffany A. Whittaker. 2010. Stay-at-home fathers' reasons for entering the role and stigma experiences: A preliminary report. Psychology of Men \& Masculinity 11, 4: 279 .

37. Anne Roeters, Tanja Van Der Lippe, and Esther S. Kluwer. 2009. Parental Work Demands and the Frequency of Child-Related Routine and Interactive Activities. Journal of Marriage and Family 7, 5: 1193 1204.

38. Anna Sarkadi, Robert Kristiansson, Frank Oberklaid, and Sven Bremberg. 2008. Fathers' involvement and children's developmental outcomes: a systematic review of longitudinal studies. Acta paediatrica 97, 2: 153-158.

39. S. H. Schwartz. 1977. Nonnative influences on altruism. Advances in experimental social psychology 10 .

40. Susan Currie Sivek. 2011. "We Need a Showing of All Hands": Technological Utopianism in MAKE Magazine. Journal of Communication Inquiry. https://doi.org/10.1177/0196859911410317

41. Wendy Wang, Kim Parker, and Paul Taylor. 2013. Breadwinner moms. Pew Research Center.

42. Modern Families + Fresh Ideas. Parenting.com. Retrieved October 23, 2015 from http://www.parenting.com/ 